\title{
Antioxidant and Antiurolithiatic Efficacy of Aerva lanata (L) Fractions by in vitro and in vivo Screening Techniques
}

\author{
Basavaraj Mrutyunjay Dinnimath ${ }^{\star 1}$, Sunil Satyappa Jalalpure ${ }^{2}$ \\ ${ }^{1}$ Department of Pharmachemistry, KLE Academy of Higher Education and Research, College of Pharmacy, Belagavi, Karnataka, INDIA. \\ 'Department of Pharmacognosy, KLE Academy of Higher Education and Research, College of Pharmacy, Belagavi and KAHER'S \\ Dr.Prabhakar Kore's Basic Science Research Center, Nehrunagar, Belagavi, Karnataka, INDIA.
}

\begin{abstract}
Background: Aerva lanata (L) Juss. Ex. Schult. (Amaranthaceae) commonly known as Pashanabheda is used traditionally in Indian system of medicines for various diseases including urolithiasis. Objective: Screening of bioactivity guided fractions of Aerva lanata (L) for antioxidant and antiurolithiatic potency. Materials and Method: The dried hydro alcoholic extract $(10 \%)$ of the whole plant was fractionated with different organic solvents like dichloromethane (fraction I), ethyl acetate (fraction II), $n$-butanol (fraction III). Based on preliminary phytochemical tests, only two fractions (II and III) were tested for antioxidant efficacy by DPPH Radical Scavenging assay and antiurolitiathic potentials on male Wistar albino rats by administering ethylene glycol $(0.75 \% \mathrm{v} / \mathrm{v})$ by oral route. Urine and blood serum were collected from all the tested animals and analyzed for the presence of calcium, oxalate, magnesium, phosphate, and BUN. Both kidneys were isolated and subjected to histopathological study. Results: Antioxidant assay has revealed that the tested fractions were equally potent as that of the standard drugs (BHT and Vitamin C). The treatment with ethyl acetate and $n$-butanol fractions significantly decreased the calcium, phosphate and BUN levels and increase in magnesium level in experimental rats $(p<0.001)$. The urine analysis has also revealed significant $(p<0.001)$ reduction in crystal size in the treated rats. Conclusion: The fractions (ethyl acetate and $n$-butanol) have shown significant antioxidant effect along with the Antiurolithiatic potency by reducing calculi through different pathways along with mild diuretic activity.
\end{abstract}

Key words: Pashanabheda, Ethylene glycol, Calcium oxalate, Antiurolithiatic activity, Antioxidant activity.

\section{INTRODUCTION}

It is being an established fact that oxidation is a major causative factor for many diseases and disorders in humans. It is reported that the chemical constituents present in medicinal plants have shown antioxidant activity by inhibiting free radicals and oxidation process. These antioxidants present in plants break the free radicals chain reactions. Among various chemicals present in medicinal plants that responsible for antioxidant activity are polyphenolic compounds ascorbic acid etc. They are reported to inhibit lipid peroxidation by inactivating lipoxygenase, to scavenge free radicals and active oxygen species by propagating a reaction cycle and to chelate heavy metal ions. ${ }^{1,2}$

Urolithiasis also known as crystalluria is the condition where urinary calculi are formed in the urinary tract. ${ }^{3}$ As there is no single effective drug available for Urolithiasis today, surgery is considered to be the best alternative. However it is expensive and not affordable for common man. Hence the natural drugs are considered to be next alternative. Pashanabheda (stone dis-
Submission Date: 26-09-2017; Revision Date: 05-12-2017; Accepted Date: 18-12-2017

DOI: 10.5530/ijper.52.3.49 Correspondence: Basavaraj M Dinnimath, Department of Pharma chemistry, KAHER'S College of Pharmacy, Hubballi, Karnataka-590010, INDIA. Phone: 9632045496 E-mail: basavaraj_dm@ yahoo.co.in

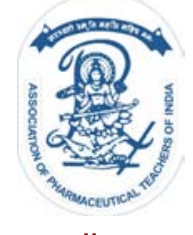

www.ijper.org 
solving) are a group of medicinal plants which are used by Ayurvedic practitioners as antiurolithiatic drugs in India. Traditionally Aerva lanata also known as Pashanabheda is used as both antiurolithiatic and diuretic. ${ }^{4-8}$

Researchers have studied different parts of Aerva lanata for various pharmacological activities such as antidiabetic, diuretic, anti-inflammatory, antioxidant, diuretic, anti-inflammatory, immunomodulatory, hepatoprotective, antimicrobial and cytotoxicity. ${ }^{9,10}$ This herb is considered to be the next best alternative Pashanabheda by Ayurvedic practioners in India as it is widely available. ${ }^{9-13}$

As the extract level work is considered to be more generalized and less specific work and we are interested to identify more specific drugs for Urolithiasis, we have carried out fractionation of the hydro alcohol extract of Aerva lanata based on its bioactivity as the fraction would be more concentrated portion containing specific group of phytochemicals and produce significant results. The results of this work shall be land mark for isolation of potent active constituents and development of lead molecules development in future. ${ }^{13,14}$

The traditional medicines system is a rich source of valuable medicinal plants but there is lack of scientific data to establish the activity of these plants. There is a need to evaluate and establish these phytochemical constituents based on their biological efficacy for the drug development. Hence we have selected Aerva lanata which is traditionally used as Pashanabheda plant (stone dissolving) for treating urolithiasis available from Western Ghats region for our present study.

\section{MATERIALS AND METHODS}

\section{Collection of Plant material}

The whole plant Aerva lanata [L] (including root) was collected from Western Ghats region of Khanapur, Taluka (Karnataka) in the month of August 2011. The plant was authenticated by taxonomist Dr. Harsha Hedge, Scientist B, RMRC, Belagavi (Specimen No-RMRC-507) and later subjected to grinding into coarse powder. The powdered dry material was used for the extraction.

\section{Extraction and Fractionation}

Dried and powdered plant material (200 g) was initially defatted with petroleum ether $\left(40-60^{\circ} \mathrm{C}\right)$ for $4 \mathrm{~h}$ and the defatted material was subjected to successive hot extraction in Soxhlet apparatus with hydro alcohol (80-20\%). After extraction, the hydro alcoholic extract was concentrated to yield semisolid residue $(10 \%)$ which is sealed and stored at $4^{\circ} \mathrm{C}$. The dried hydro alcoholic extract was dissolved in water and then fractionated with dichloromethane (fraction I), ethyl acetate (fraction II), $n$-butanol (fraction III). ${ }^{15,16}$

\section{2,2-Diphenyl-1-Picrylhydrazyl Scavenging Assay \\ (DPPH) Radical}

To study the antioxidant potency of the fractions, the effect of each fraction against DPPH radical was determined according to the method described by Brand-Williams, Cuvelier and Berset (1995) with minor modifications. In brief, $0.1 \mathrm{~mL}$ of the sample at different concentrations $(12.5,25,50,100,200 \mu \mathrm{g} / \mathrm{mL}$ dissolved in methanol) was added to $3.9 \mathrm{~mL}$ of DPPH solution (25 mg/L in methanol). An equal amount of methanol and DPPH served as the control. The mixture was shaken and left at room temperature for $30 \mathrm{~min}$, the absorbance was measured at $517 \mathrm{~nm}$ on UV-VIS Spectrophotometer (Shimadzu). The inhibitory percentage of DPPH was calculated according to the following equation:

$$
\text { DPPH } \% \text { inhibition }=\frac{\text { blank }- \text { sample }}{\text { blank } !} \times 100
$$

Where a blank is the absorbance of the control reaction (containing all reagents except the test sample), and A sample is the absorbance of the extracts/standard.

The $\mathrm{IC}_{50}$ value is the amount of antioxidant necessary to decrease the initial DPPH concentration by $50 \%$ which was calculated from the results and used for comparison. Ascorbic acid and Butyl Hydroxy Toluene were used as standards. ${ }^{17-22}$

\section{Animals for antiurolithiatic study}

Male Wistar albino rats weighing 150-200 g were purchased from Sri Venkateshwara traders, Bangalore. They were housed in acryl fiber cages at $23 \pm 2{ }^{\circ} \mathrm{C}$, humidity $50 \pm 1 \%$ and were kept on a $12 \mathrm{~h}$ light/dark cycle. They were fed with standard chow feed (Amrut Laboratories, Sangali) and water ad libitum and acclimatized for 15 days before the study. Experimental protocols reported in this study were approved by the Institution Animal Ethical Committee of CPCSEA, Govt. of India (IAEC-Resolution No-13, 31-07-2010) and carried out in accordance with OECD (Organisation for Economic Co-operation and Development) guidelines.

\section{Chemicals and drugs}

Ethylene glycol (0.75\%) and Sodium Carboxy Methyl Cellulose were purchased from Himedia Lab (Mumbai) and Loba Chemie (Mumbai) respectively. Standard drug Cystone was purchased from Himalaya Herbal Healthcare, Bangalore. Demineralised water and analytical grade chemicals/solvents were procured from local market. 


\section{Drug administration}

The standard drug and fractions were administered orally through stainless steel oral feeding tube. Sodium Carboxy Methyl Cellulose 1\% of the weight was added to the fractions for preparing the doses.

\section{Acute toxicity assay}

Acute toxicity assay was performed as per OECD guidelines 423 (limit test) for hydroalcohol extract of Aerva lanata. Six male Wistar albino rats (three animals in each step) were randomly selected. The animals were kept fasting for overnight providing only water. The extract was administered orally at one dose level of $2000 \mathrm{mg} / \mathrm{kg}$ b.w of the animals. In further rats were observed continuously for the first $4 \mathrm{~h}$ and then periodically up to $24 \mathrm{~h}$ for toxic symptoms and mortality. The number of deaths was noted to calculate $\mathrm{LD}_{50}$ and therapeutic dose for extract.

Based on the results of the above study equivalent doses were calculated for fractions ( II and III) based on their yield values. Since the hydro alcoholic extract was found to be safe no separate toxicity study was performed for the fractions (.recommendations of IAEC).

Evaluation of antiurolithiatic activity of fractions by ethylene glycol $(0.75 \% \mathrm{v} / \mathrm{v})$ induced rats model

A curative study for the fractions of Aerva lanata was carried out using ethylene glycol $(0.75 \% \mathrm{v} / \mathrm{v})$ induced urolithiasis model for 28 days. This study aimed at screening both the fractions (II and III) for antiurolithiatic activity in male wistar albino rats. The animals were distributed into seven groups containing six each. The group I served as control and fed with normal rat food and water ad libitum. Group II to VII received ethylene glycol $(0.75 \% \mathrm{v} / \mathrm{v})$ orally in drinking water from day 1 to day 28 for the induction of renal calculi. Group II served as disease induced group. Group III received standard drug Cystone $(750 \mathrm{mg} / \mathrm{kg} \mathrm{b.w})$ from $14^{\text {th }}$ day to $28^{\text {th }}$ day. Group IV received fraction II (20 mg/kg b.w.), group V received fraction II ( $40 \mathrm{mg} / \mathrm{kg}$ b.w), group VI received fraction III (20 mg/kg b.w.) and group VII received fraction III ( $40 \mathrm{mg} / \mathrm{kg} \mathrm{b.w})$ from $14^{\text {th }}$ day to $28^{\text {th }}$ day.

Urine and serum biochemical analysis was carried out on $28^{\text {th }}$ day of the study for calcium, oxalate, magnesium, phosphate, and blood. The blood serum was collected from experimental animals through retro orbital plexus under anesthetic conditions. The both kidneys were harvested and subjected to histopathological study for the presence of calculus in kidneys ${ }^{23,24,25}$

\section{Statistical analysis}

The results were expressed as mean \pm SEM. Statistical significance was calculated using One Way Analysis of
Variance test (ANOVA), followed by Dunnet's $t$-test, value less than $p<0.001$ were considered as statistically significant.

\section{RESULTS}

\section{Antioxidant activity of the fractions}

The study of fractions (II and III) by DPPH method was carried out using Ascorbic acid and BHT as standard drugs. The highest scavenging activities on DPPH radicals were $79.44 \%$ for Fraction-II and $91.58 \%$ for Fraction-III at $200 \mu \mathrm{g} / \mathrm{mL}$ as compared to $89.13 \%$ and 61.01\% for Ascorbic acid (Vitamin C) and BHT respectively at the same concentrations (Figure 1).

\section{Urine analysis}

The urine output of normal and experimental rats was collected on $14^{\text {th }}$ and $28^{\text {th }}$ day and volume was measured to know the possible increase in urine and its volume. The urine volume in the rats treated with the fractions was significantly increased in comparison with that of normal rats (Table 1).

\section{Calculi analysis}

Urine samples of normal, disease induced and treated animals were analyzed for the presence of calculi under camera Lucida microscope. This study has revealed that there was no stone formation in normal animals whereas urine samples of disease induced animals has revealed the presence of stones of different size and shapes. Later, the urine samples of treated animals has revealed that the amount of calculi was significantly reduced in treated animals urine sample (Figure 9-12)

\section{Biochemical analysis}

From the urine analysis it was found that the levels of calcium, oxalate and phosphate were high in the disease induced animals, whereas the levels of these ions were found to be significantly less $(P<0.001)$ in the urine samples of the animals treated with the fractions (Table 1) whereas the level of magnesium was high (Figure

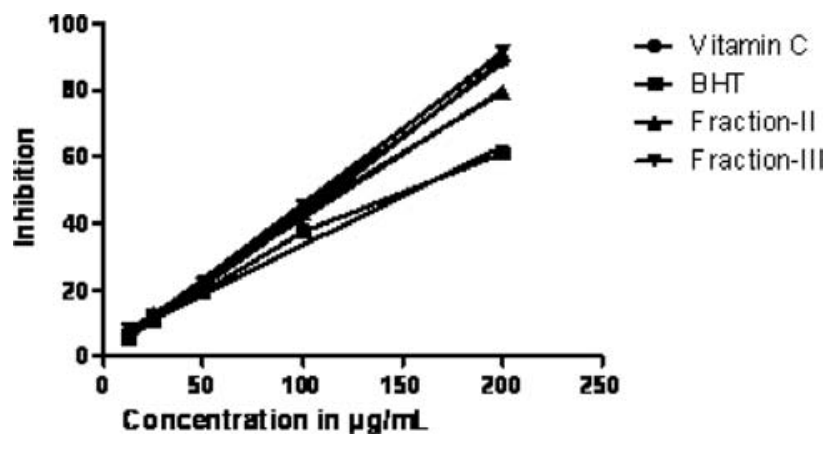

Figure 1: DPPH Scavenging activity study. 


\begin{tabular}{|c|c|c|c|c|c|}
\hline \multicolumn{2}{|c|}{ Table 1: Urine volume of experimental rats (in $\mathrm{ml})$. } \\
\hline Days & Normal group & Disease induced group & $\begin{array}{c}\text { Std drug } \\
\text { (Cystone) treated }\end{array}$ & Fraction II treated & Fraction III treated \\
\hline 14 & $19.47 \pm 0.3$ & $21.65 \pm 0.5$ & $27.12 \pm 0.8$ & $23.53 \pm 0.1$ & $23.46 \pm 0.1$ \\
\hline 28 & $19.38 \pm 0.2$ & $22.02 \pm 0.3$ & $21.53 \pm 0.4$ & $24.35 \pm 0.1$ & $24.56 \pm 0.2$ \\
\hline
\end{tabular}

Values with $p<0.001$ was considered as significant level

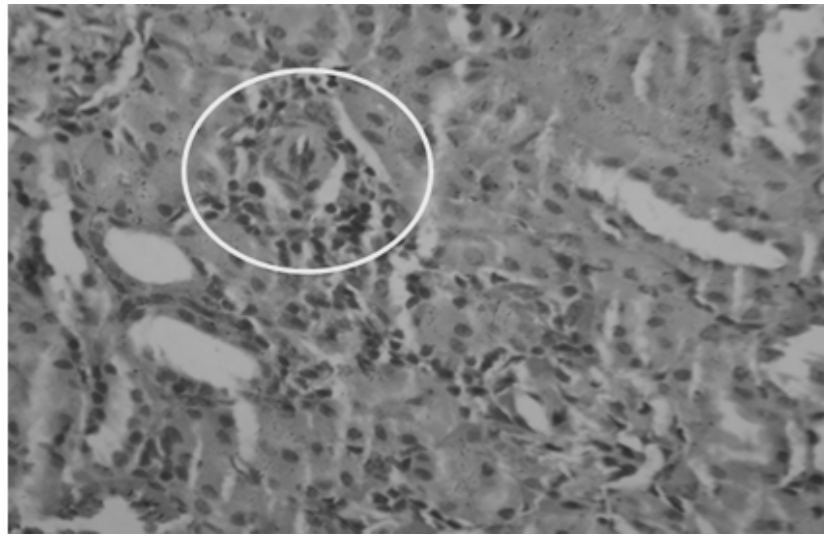

Figure 2: Kidney section of disease induced animal showing congestion and inflammation.

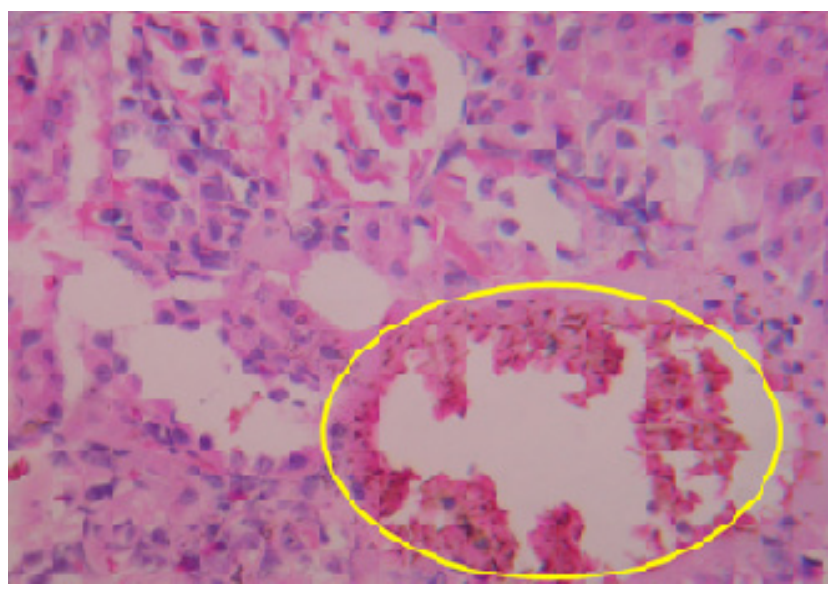

Figure 3: Kidney section of disease induced animal showing Haemorrhage.

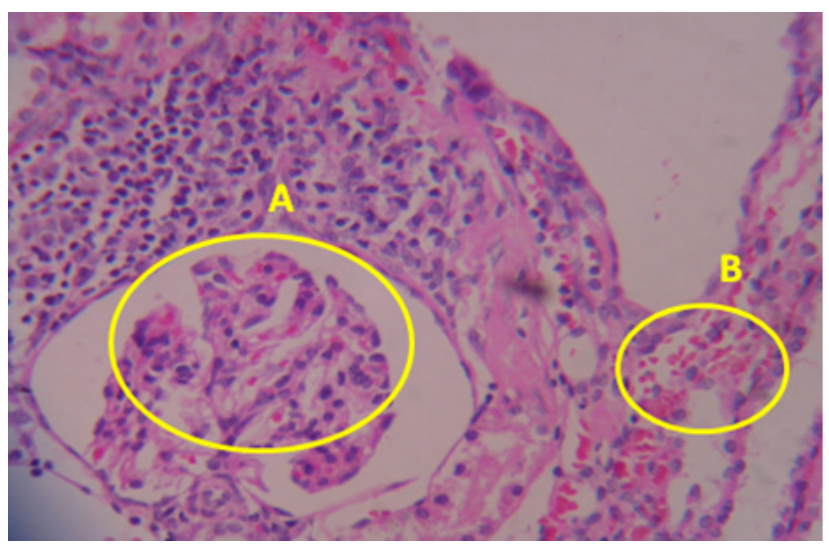

Figure 4: Kidney section of the animal treated by fraction II (AEF II)

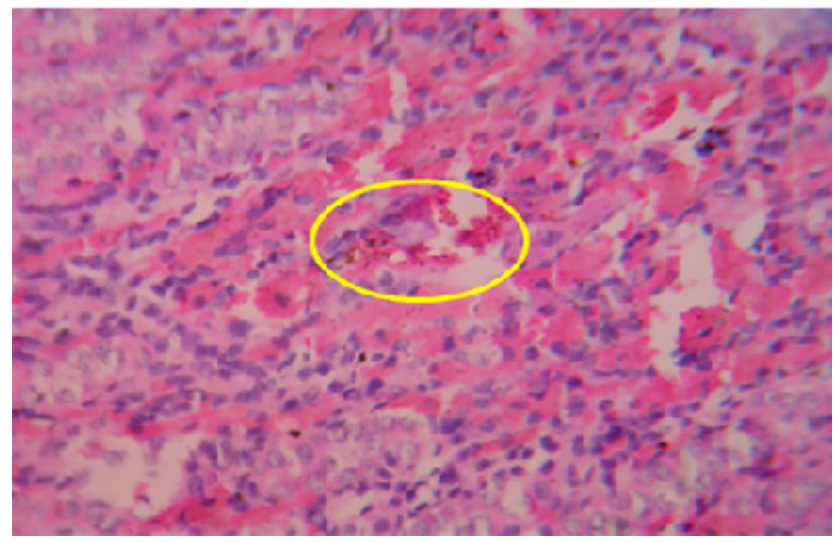

Figure 5: Kidney section of the animal treated by fraction II (AEF II).

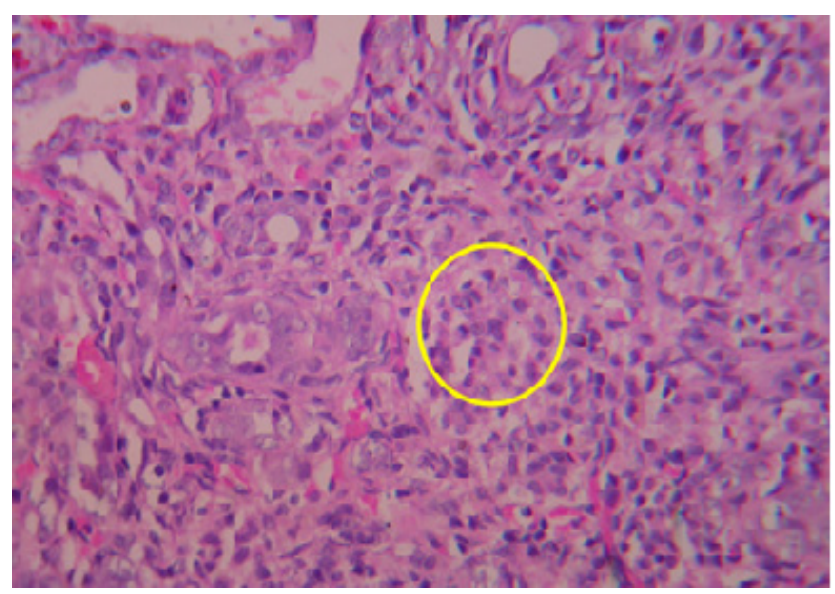

Figure 6: Kidney section of the animal treated by fraction III (AEF III).

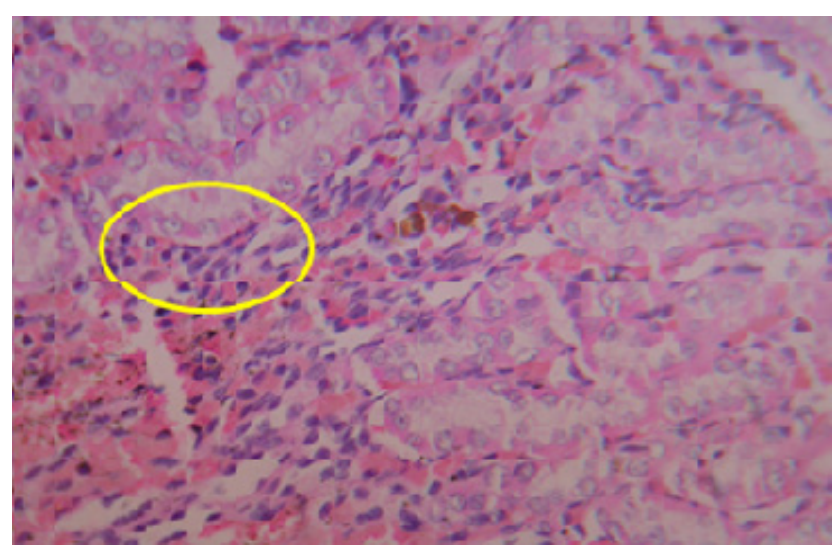

Figure 7: Kidney section of the animal treated by fraction III(AEF III) 


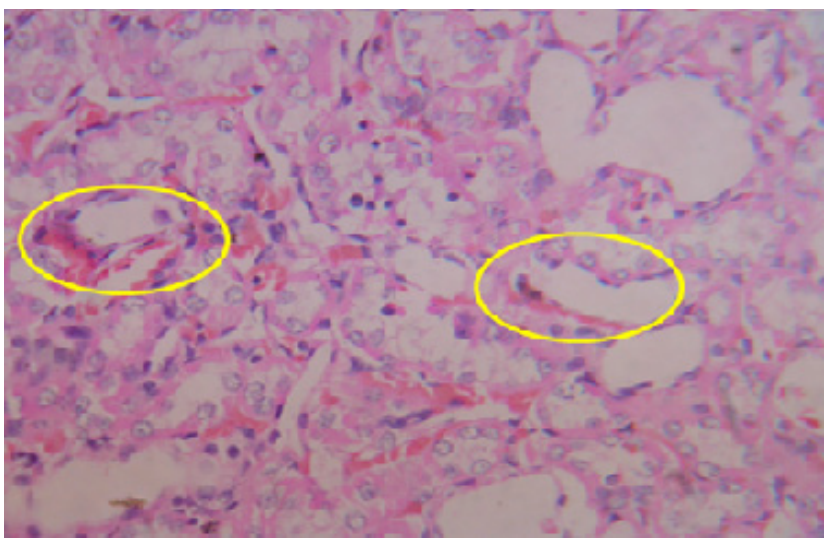

Figure 8: Kidney section of the animal treated by fraction III -reduction in tubular congestion.

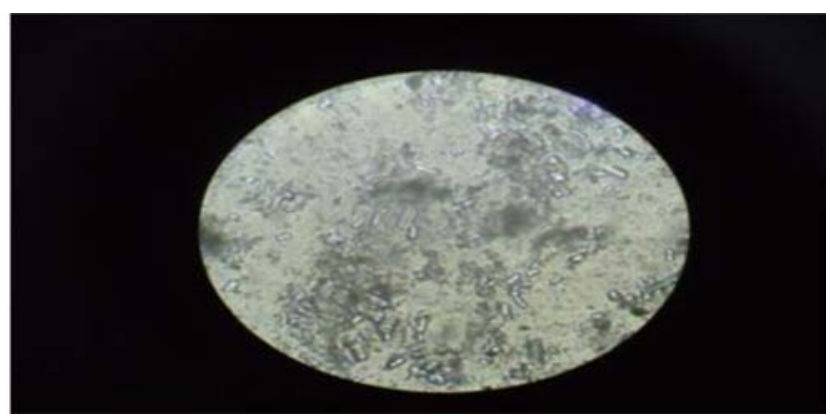

Figure 9: Calculi in disease induced animal's urine under the microscope.

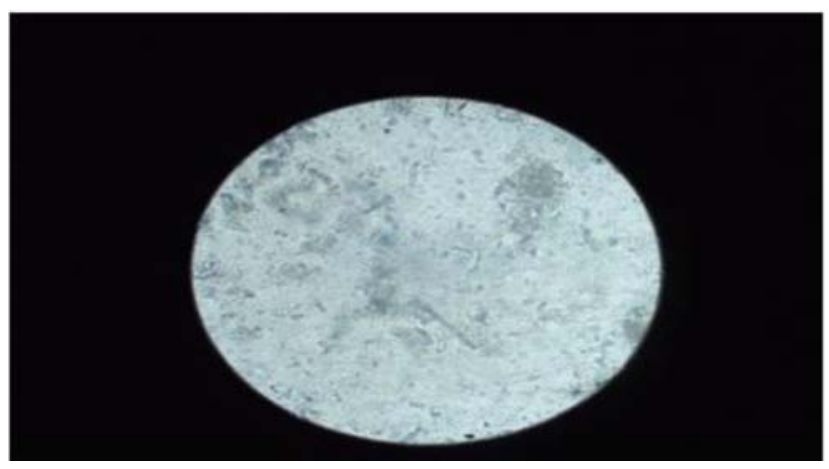

Figure 10: Urine microscopy of normal animal.

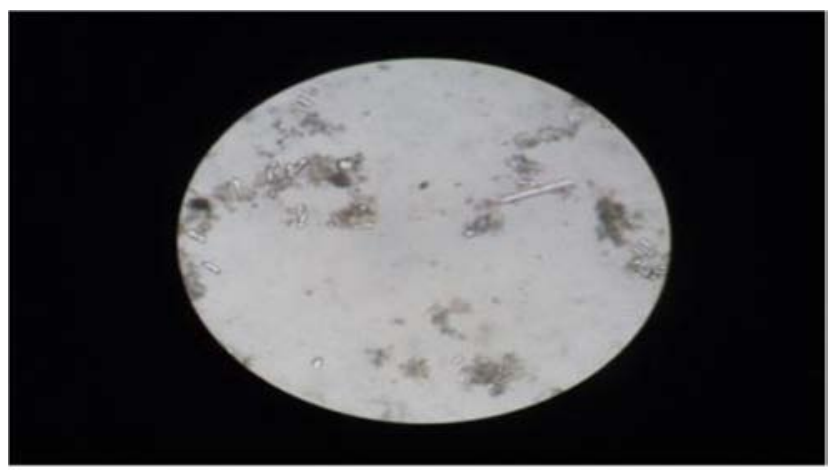

Figure 11: Calculi in urine sample of animal treated by fraction II.

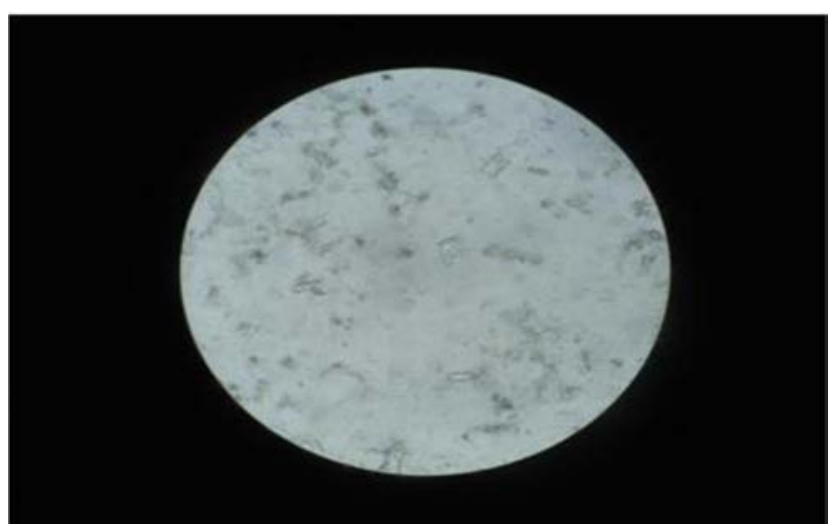

Figure 12: Urine sample of animal treated by fraction III.

13-15). The tested fractions have reduced the elevated levels of calcium, oxalate and phosphate in the urine of animals (Group IV to Group VII) and increased the level of $\mathrm{Mg}$. Urine samples of treated animals showed the $\mathrm{pH}$ of the urine at $>7$ which was found to be alkaline.

\section{Histopathological data}

The pathological changes in the harvested kidney of normal and experimental rats are shown in Figure 2-8. Kidneys of all animals isolated after 28 days were subjected for histopathological study. The sections of kidneys of disease induced with ethylene glycol have shown large quantity of calculi deposition whereas in the kidney section of the treated groups, calculi deposition was significantly less (Figure 4-8). The kidney section of rats treated with ethylene glycol $(0.75 \% \mathrm{v} / \mathrm{v})$ showed deposition of micro crystals. There was tubular damage and inflammatory cells were also noticed. Kidney section of animals treated with fractions (II and III) showed improvement of the above symptoms and reduced crystal deposition.

\section{Spectral (LCMS) study of fractions}

By subjecting the fractions to LCMS study to know the phytochemicals present, it was noticed that both the fractions contain various phytochemicals mainly the polyphenolic compounds such as flavonoids, glycosides, saponins which were present in the fractions (Figure 20,21) are given in the Table 3

\section{DISCUSSION}

As the evaluation of fraction/s of a plant extract responsible for a biological activity would be more scientific than the conventional study of evaluating plant extract alone since the fractions are more concentrated portion consisting of specific group of phytochemicals responsible for an activity. This could also be useful for drug discovery from plants. This fact has given us 
an impetus to carry out the present research work to identify specific fraction/s containing specific group of phytochemicals responsible for a biological activity as nowadays some herbal companies are focusing their research in this direction.

The plant phytochemicals such as flavonoids, sapiens and terpenoids are reported to be responsible for antioxidant activity which in turn helps in showing various other biological activities. The plant selected for the present Antiurolithiatic activity also found to contain these reported phytochemicals. ${ }^{13}$ Hence to study the antioxidant and antiurolithiatic potency of the fractions from Aerva lanata plant extract were subjected to the reported study.

The results of antioxidant study has indicated that both the fractions (II and III) were equally potent as compared with the standards. Hence these two fractions have good antioxidant efficacy as that of the plant and eligible to produce good biological results in various diseases. This could also be the reason for the tested fractions have shown significant antiurolithiatic efficacy and diuretic activity also in the present study.

The present study of antiurolithiatic potentials of the fractions which is based on the curative treatment designed to evaluate the antiurolithiatic potential of the fractions rich in flavanoids, triterpenoids and saponins. ${ }^{23,24}$ This study has mainly examined and revealed the antiurolithiatic efficacy of the two fractions ( $n$-butanol and ethyl acetate) of hydro alcoholic extract from Aerva lanata on calculi induced experimental rats by ethylene glycol $(0.75 \% \mathrm{v} / \mathrm{v})$ along with significant diuretic activity. ${ }^{25}$ Since fraction I DCM) did not show the presence of targeted phytochemicals (flavanoids, triterpenoids and saponins) in the preliminary phytochemical tests and spectral analysis, whereas fraction II and fraction III have shown their presence (phytoconstituents) which are reportedly responsible for antiurolithiatic activity in different plants. Hence these two fractions were subjected for in vivo screening of antiurolithiatic activity.

The urine microscopy revealed that concentration of various ions was altered drastically in urine after the treatment with the fractions (II and III). The urine of normal group of rats has shown absence of any crystalline structures whereas the urine sample of disease induced animals has shown the presence of micro crystalline structures (pentagonal) and the urine of treated animals has shown the presence of small fragments.

The concentrations of calcium, oxalate, phosphate, and BUN were low in normal rats whereas, the concentration of these ions was increased in the urine samples of the disease induced animals along with a decrease in the magnesium level on the $28^{\text {th }}$ day (Figure 13-15). A significant decrease in the level of these ions and an increase in the level of magnesium was observed in the urine sample of the animals treated with the fractions II and III ( Figure 18). This shows the diuretic effect of fractions on reducing the levels of the ions as well as increasing the level of magnesium ion (Figure 16-19) which is considered as stone inhibitor reportedly inhibit stone nucleation as it is reportedly interfere in the formation of calcium oxalate crystals. Hence calculi formation and deposition may be reduced which may be due to the phytochemicals such as flavanois and terpenoids present in both the fractions. ${ }^{27,28}$

The urine samples of normal and treated animals were collected and a comparative analysis was carried out for the weight of the animals and volume of urine before

\section{Calcium}

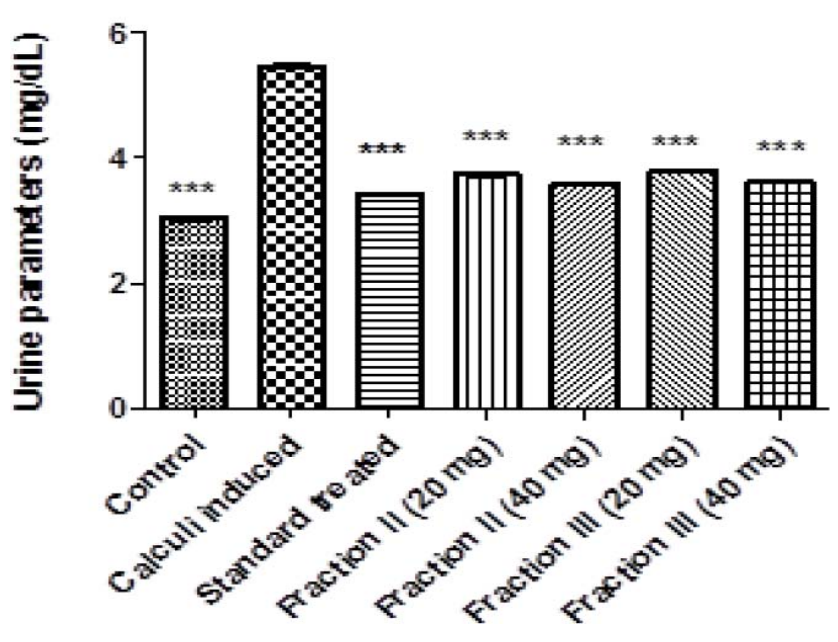

Figure 13: Effect of Aerva lanata fractions on urinary parameter (Calcium) in normal and treated animals.

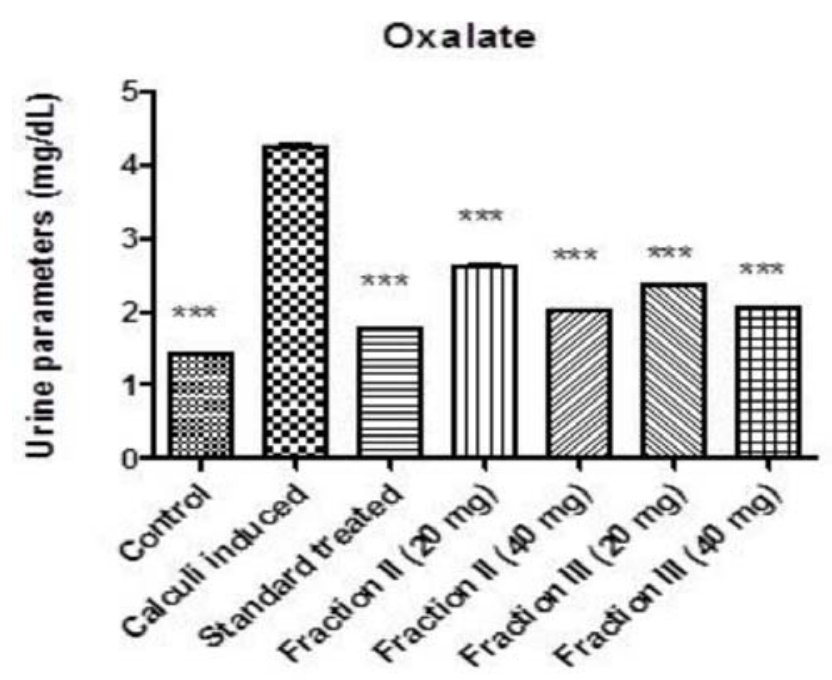

Figure 14: Effect of Aerva lanata fractions on urinary parameter (Oxalate) in normal and treated animals. 


\section{Phosphate}

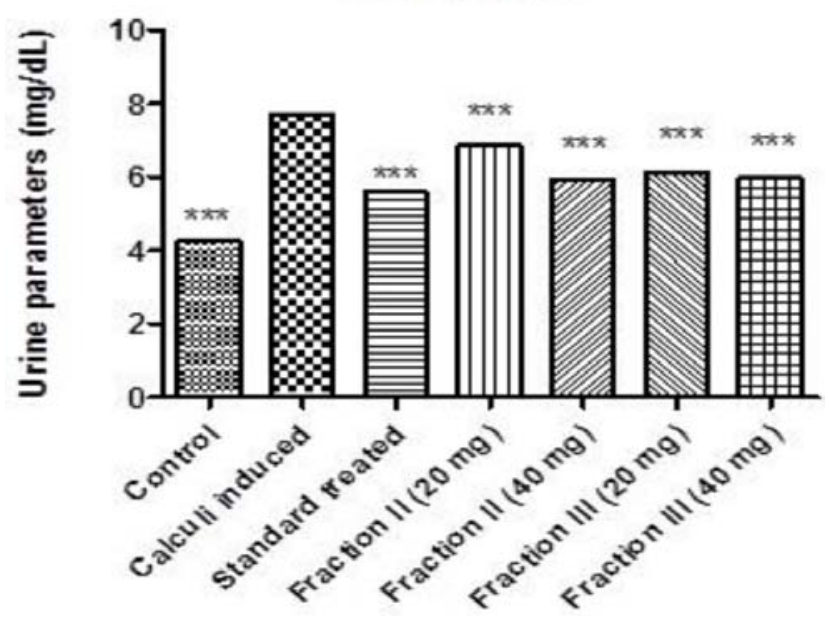

Figure 15: Effect of Aerva lanata fractions on urinary parameter (Phosphate) in normal and treated animals.

\section{Calcium}

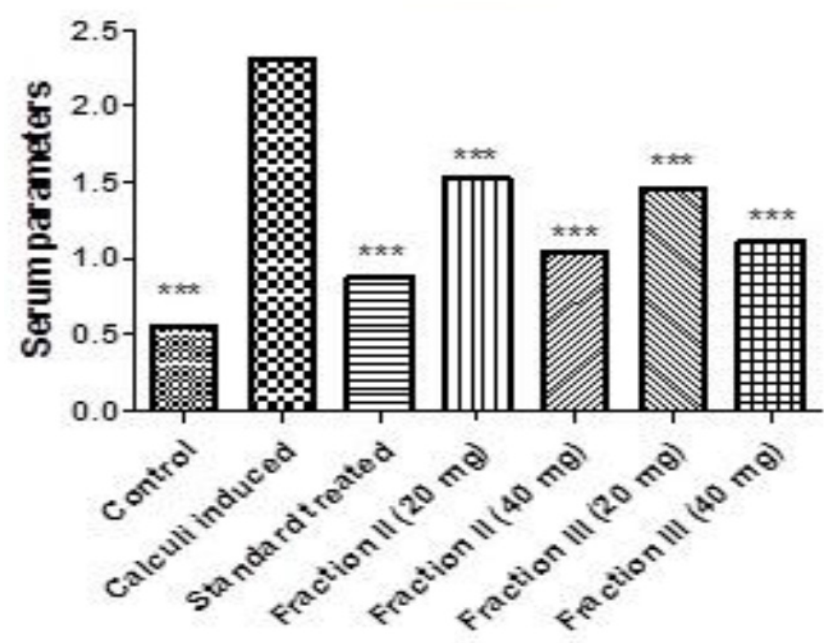

Figure 16: Effect of Aerva lanata fractions on serum parameter (Calcium) in normal and treated animals.

and after treatment. This analysis has revealed that there was significant increase in and volume of urine in the treated animals with fraction II and fraction III (Table 1) and the weight of the animals (Table 2). This indicate the diuretic effect of the fractions (II and III) which in turn that of the plant. Urine samples of treated animals also revealed the $\mathrm{pH}>7$ which indicate the effect of plant fractions (II and III) on $\mathrm{pH}$ of urine in tested animals by shifting it towards alkaline side, which is another good feature of an ideal antiurolithiatic drug. Urine microscopy under electronic microscope has also revealed that there was no calculi found in normal animal urine sample whereas the disease induced animal urine samples have revealed the presence of calculi of different

\section{BUN}

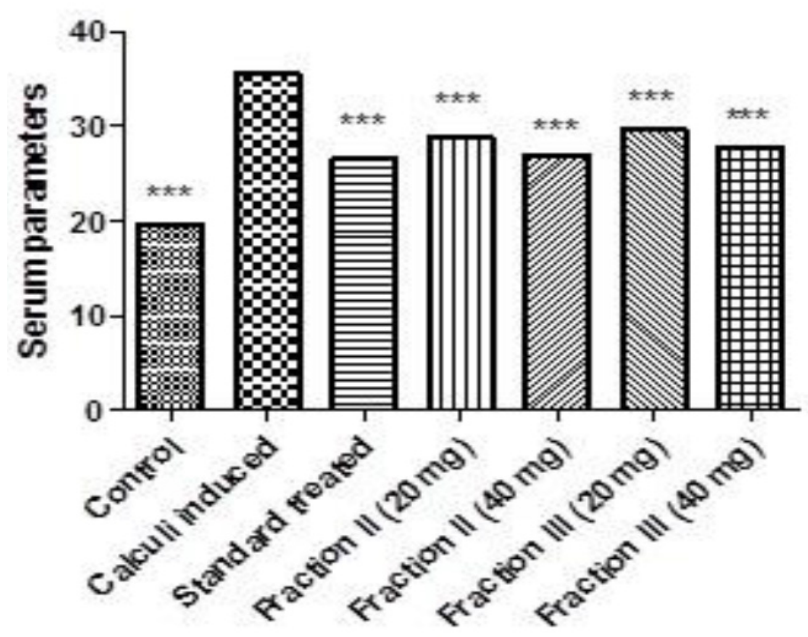

Figure 17: Effect of Aerva lanata fractions on serum parameter (BUN) in normal.

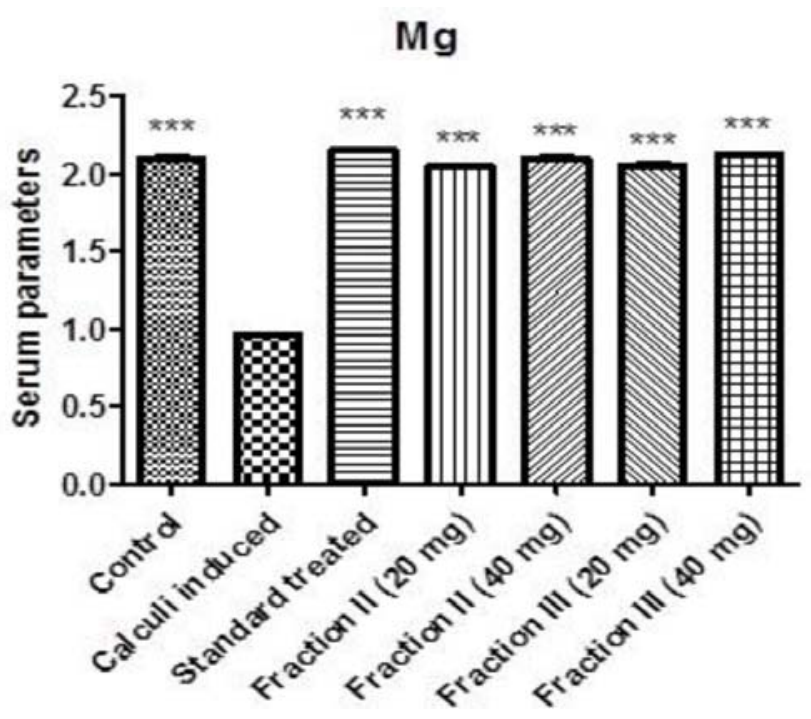

Figure 18: Effect of Aerva lanata fractions on serum parameter (Magnesium) in normal and treated animals and treated animals.

size and shapes. The urine samples of experimental animals treated with fractions II and III has shown significant reduction in quantity of stones compared to disease induced urine samples. This confirms that there is significant effect of the fractions in the reduction of stones in treated animals (Figure 11,12).

Scanning Electron Microscopic (SEM) examination of harvested kidney showed ultra-structural detectable changes in the proximal convoluted tubular epithelial cells (PCT) in the test groups, compared to the control group. The glomeruli in all three groups (treated with standard drug and $n$ butanol fraction of both high and low doses) did not show any ultra structural changes. The PCT epithelial cells were considered normal when 


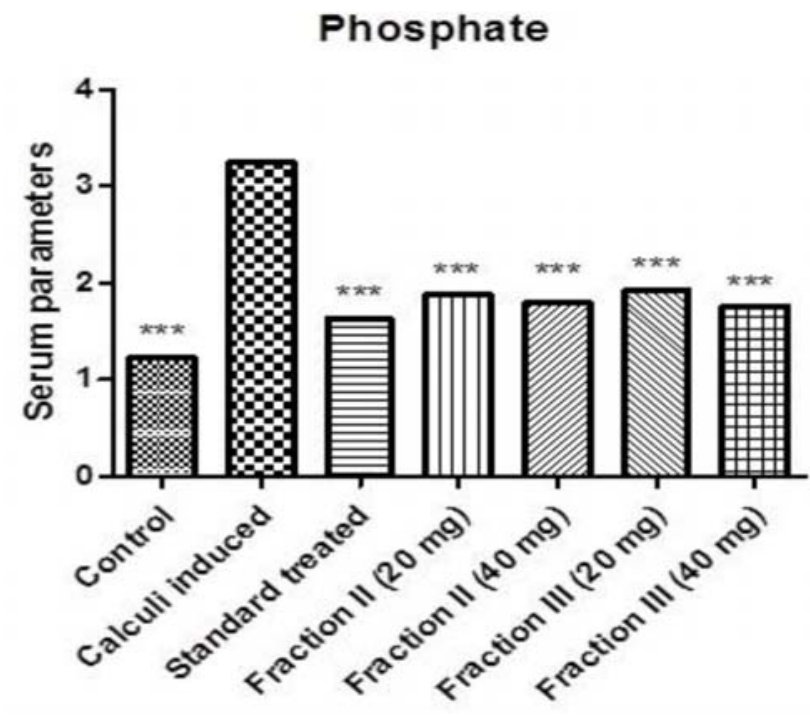

Figure 19: Effect of Aerva lanata fractions on serum parameter (Phosphate) in normal and treated animals.

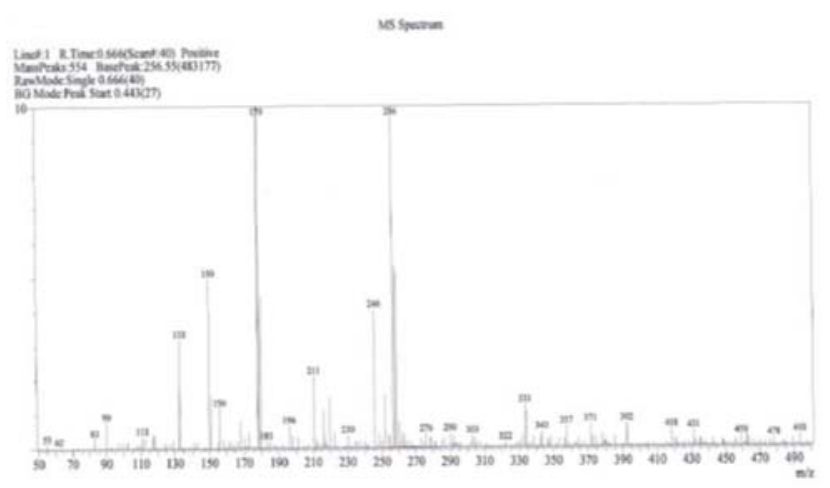

Figure 20: LCMS of fraction II.

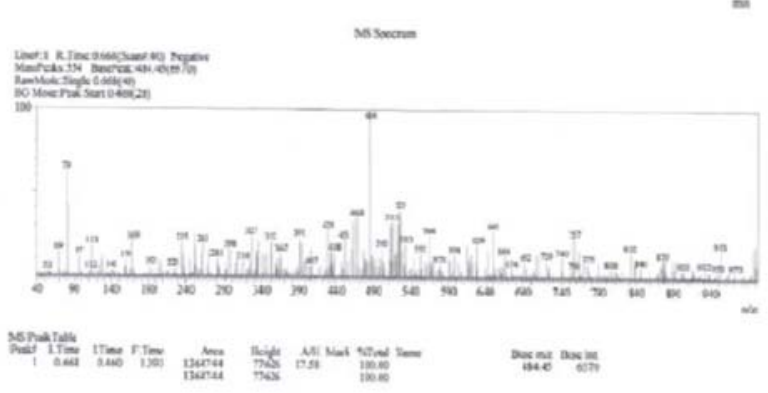

Figure 21: LCMS of fraction III.

the brush border was found to be intact and clear. The cell organelles were also intact in the epithelial cells. ${ }^{29,30}$ From the histopathological data it is evident that there is slight inflammation in the renal tubules (Figure 4) which gives an indication that there is a slight possibility that the inflammation was not reduced at the dose administered and further study is needed to evaluate the anti-inflammatory effects of the fractions. The histopathological study has revealed that the hemorrhage is reduced significantly in comparison with disease induced kidney section (Figure 5). PCT is responsible for reabsorption of $60-65 \%$ of filtered water from the tubular lumen. Disrupted brush border may affect the reabsorption of solutes from the tubular lumen leading to a reduction in the passive reabsorption of water at the level of PCT. ${ }^{30}$

\begin{tabular}{|c|c|c|c|c|c|}
\hline \multicolumn{5}{|c|}{ Table 2: Weight of experimental rats (in gm). } \\
\hline Days & Normal group & Disease induced group & Treated with std drug & Fraction II treated & Fraction III treated \\
\hline 14 & $150 \pm 10.8$ & $165 \pm 12.6$ & $155.14 \pm 5.3$ & $157.4 \pm 5.3$ & $156.5 \pm 4.4$ \\
\hline 28 & $174 \pm 10.9$ & $186 \pm 14.5$ & $178.5 \pm 5.3$ & $179.3 \pm 5.3$ & $168.2 \pm 62$ \\
\hline
\end{tabular}

Values with $p<0.001$ was considered as significant level

\begin{tabular}{|c|c|c|}
\hline Phytochemicals & Molecular weight & Peak value in the LCMS \\
\hline Isoflavone & 317 & 316 (fraction III) \\
\hline Isorhamnetin & 304 & 303 (fraction II) \\
\hline Quercetin & 333 & 333 (fraction II) \\
\hline Myrcetin & 318 & 319 (fraction III) \\
\hline Methoxyflavone & 404 & 404 (fraction III) \\
\hline Betulin & 442 & 442 (fraction III) \\
\hline Glucopyranoside & 448 & 448 (fraction II) \\
\hline Isoquercetin & 464 & 465 (fraction III) \\
\hline Ursolic acid & 457 & 457 (fraction II) \\
\hline Rhamnoside & 598 & 598 (fraction III) \\
\hline Rutin & 610 & 610 (fraction III) \\
\hline Isothamnetin-3-0-rutinoside & 629 & 629 (fraction III) \\
\hline
\end{tabular}


The antiurolithiatic effect of these fractions on calculi may be due to their effect on the enzymes oxalate oxidase which participates in calculi formation as well as its effect partly, in reducing the size of the calculi. This activity may be due to the presence of flavonoids, saponins and triterpenoids in the fractions which might interfere in the supersaturation and stone deposition in urine. ${ }^{26}$

As the fractions have shown the presence of phytochemicals in the preliminary phytochemical investigations reported earlier, it was necessary to identify them in a more scientific manner by subjecting them to spectral study. The LCMS spectra of both the fractions have shown the presence of different polyphenolic compounds around their molecular ion (based on molecular weight) as given in Table 3. This confirmed the presence of flavonoids, glycosides, saponins etc. The important phytochemicals which may be responsible for the antioxidant and antiurolithiatic activity may be Betulin, Quercetin, Ursolic acid etc which needs to be confirmed by conducting a separate study for the isolated compounds. Hence this LCMS study gives information for the isolation of potent compounds and their screening which may be helpful for the drug discovery in future. ${ }^{34}$ Hence the tested fractions II and III of the plant extract have shown significant antiurolithiatic activity along with diuretic activity which was however, found to be dose dependent and due to the phytoconstituents such as flavonoids and terpenoids present in fractions.

\section{CONCLUSION}

In our present study, the whole plant Aerva lanata which is also known as Pashanabheda in western Ghats was subjected to bioactivity guided fractionation with different organic solvents such as DCM (fraction I), ethyl acetate (fraction II) and $n$-butanol (fraction III) and the fraction II and III after preliminary phytochemical study were subjected to in vitro antioxidant study by DPPH method followed by in vivo antiurolithiatic activity with two different doses $(20 \mathrm{mg} / \mathrm{kg}$ body weight and $40 \mathrm{mg} / \mathrm{kg}$ body weight). The results have shown significant antioxidant activity as compared to standard drugs and antiurolithiatic activity for these two fractions on calculi induced $(0.75 \% \mathrm{v} / \mathrm{v}$ ethylene glycol $)$ animals along with diuretic effect which however, need to be studies separately. The presence of polyphenolic compounds such as flavonoids, saponins, and triterpenoids may be responsible for these activities. ${ }^{33}$ The LCMS data of the fractions gives us an insight regarding the phytochemicals present in them. This study gives an insight into the specific scientific reasons that are responsible for the antiurolithiatic activity of the plant as well as gives direction for the isolation of potent active constituent/s from the fractions (II and III) for the drug development.

\section{ACKNOWLEDGEMENT}

Authors thank KLE University and Principal, KLESs' College of Pharmacy, Belagavi for the present research. Authors also thank Principal, KLEU'S College of Pharmacy, Hubballi. Authors also thankful to Mr. Santosh B Patil for his assistance in this project.

\section{CONFLICT OF INTEREST}

Authors declare that there is no conflict of interest exists.

\section{ABBREVAITIONS USED}

AEF: Code for Fraction/s; DPPH: Diphenyl-1-Picrylhydrazyl; BHT: Butylated Hydroxytoluene; DCM: Dichloro Methane; SEM: Scanniong Electron Microscopy; BUN: Blood Urea Nitrogen; OECD: Organization for Economic Cooperation and Development; LCMS: Liquid Chromatography and Mass Spectroscopy; PCT: Proximal Convoluted Tubule.

\section{REFERENCES}

1. Veeru P, Mishra P, Mishra M. Screening of medicinal plant extracts for antioxidant activity. J. Med. Plants Res. 2009;3(8):608-12.

2. Kumar G, Karthik L, Rao KV. Phytochemical composition and in vitro antioxidant activity of aqueous extract of Aerva lanata (L.) Juss. Ex Schult. Stem (Amaranthaceae). Asian Pac J Trop Med. 2013;6(3):180-7.

3. Pareta SK, Patra KC, Mazumder PM, Sasmal D, et al. Establishing the Principle of Herbal Therapy for Antiurolithiatic Activity: A Review J Pharmacol Toxicol. 2011;6(3):321-3

4. Adepu A, Narala S, Ganji A, Chilvalvar S. A Review on Natural Plant: Aerva lanata. Int. J. Pharma. Sci. 2011;3(6):398-402.

5. Venugopal SN. Herbal stone crushers; The Pashanabheda. Medplant-Envis Newsletter on medicinal plants. 2009;1(2):6-9.

6. Butterweck V, Khan SR. Herbal Medicines in the Management of Urolithiasis: Alternative or complementary? Planta Med. 2009;75(10):1095-103.

7. Atmani F, Slimani Y, Mimouni M, Hacht B. Prophylaxis of calcium oxalate stones by Herniaria hirsuta on experimentally induced nephrolithiasis in rats. Br J Urol. 2003; 92(1):137-9

8. Bhattacharjee A. Phytochemical and ethno-pharmacological profile of Crataeva nurvala Buch-Hum (Varuna): A review. Asian Pac J Trop Biomed. 2012;2(2):1162-8.

9. Gadge NB, Jalalpure SS. Curative treatment with extracts of Bombax ceiba L. (Bombacaceae) fruit reduces risk of calcium oxalate urolithiasis in rats. Pharm. Biol. 2012;50(3):310-7.

10. Gunatilake M. Aerva lanata (Polpala): Its effects on the structure and function of the urinary tract. Phcog. Res. 2012;4(4):181-4.

11. Ventrichelvan T. Diuretic and antiinflammatory activities of Aerva lanata in rats. Indian J. Pharm. Sci. 2000;62(4):300-3

12. Hadjzadeh MSR. The preventive effect of $N$-butanol fraction of Nigella sativa on ethylene glycol-induced kidney calculi in rats. Phcog. Mag. 2011;7(28):338-43.

13. Rajesh RK, Chitra K, Paarakh PM. Aerva lanata (Linn.) Juss. Ex Schult. An Overview. Asian Pac J Trop Biomed. 2011;2:36-40. 
14. Dinnimath BM, Jalalpure SS. in Silico Antiurolithiatic Screening of Aerva lanata (L) isolated constituents. IJPER. 2015;49(2):126-33.

15. Handa SS, Khanuja SPS, Longo G, Dutt DR. 2008. Extraction Technologies for Medicinal and Aromatic Plants: Int Centre for Science and High Technology,(Trieste).

16. Herath HM, Gunatilake M, Lokuhetty D, Wijayabandara J. A preliminary investigation on the effects of polpala (Aerva lanata) on the structure and function of urinary tract of rats. Ceylon J. Med. Sci. 2005;48:33-6

17. Brand-Williams W, Cuvelier ME, Berset CL. Use of free radical method to evaluate antioxidant activity. Lebensm Wiss Technology. 1995;28(1):25-30.

18. Marinova G, Batchvarov V. Evaluation of the methods for determination of the free radical scavenging activity by DPPH. BULG J AGRIC SCI. 2011;17(1):11-24.

19. Annapandian VM, Rajagopal SS. Phytochemical Evaluation and In vitro Antioxidant Activity of Various Solvent Extracts of Leucas aspera (Willd.) Link Leaves. Free Radicals and Antioxidants. 2017;7(2):166-71.

20. Kefayati Z, Motamed SM, Shojaii A, Noori M, Ghods R. Antioxidant activity and phenolic and flavonoid contents of the extract and subfractions of Euphorbia splendida Mobayen. Pharmacognosy Res. 2017;9(4):362-5.

21. Amor L, Belhattab R. Antioxidant activity of aqueous extracts from Crataegus oxyacantha leaves. Pharmacognosy Communications. 2015;5:229-232.

22. Paramasivam R, et al. Phytochemical Screening, Antioxidant activity of Aerva lanata (L) -An In vitro study. Asian. J. Pharm. Clin. Res. 2012;5(2):77-81.

23. Mamta FS, Bisht S, Sajwan R. Evaluation of Antiurolithiatic Activity of Combination of Phyllanthus niruri and Aerva lanata in Ethylene Glycol induced Urolithiasis in Rats. J Pharm Res. 2014;2:18-21.

24. Nadkarni KM. Indian Materia Medica, Bombay Popular Prakashan. 1976;1:1142.
25. Parmar NS, Shiv-Prakash. Screening methodology in Pharmacology, Narosa Publishing House, and New Delhi. 2006;246.

26. Dinnimath BM, Jalalpure SS. Spectral Analysis of Fractions of Aerva lanata (L). Indian Journal of Natural Products. 2012;28(2):14-8

27. Ghelani H, Chapala M, Jadav P. Diuretic and antiurolithiatic activities of an ethanolic extract of Acorus calamus L. rhizome in experimental animal models. Tradit Complement Med. 2016;6(4):431-6.

28. Pareta SK, Patra KC, Harwansh R. In vitro calcium oxalate crystallization inhibition by Achyranthes indica Linn. Hydroalcoholic extract: An approach to antilithiasis. Int J Pharm Bio Sci. 2011;2:432-7.

29. Touhami M, Laroubi A, Elhabazi K, Loubna F, Zrara I, Eljahiri Y, et al. Lemon juice has protective activity in a rat urolithiasis model. BMC Urology. 2007;7:18-21.

30. Ahmed S, Hasan MM, Mahmood ZA. Growth patterns of monosodium urate monohydrate (gouty and urinary) crystals in gel: An in vitro study. Pak J Pharm Sci. 2017;30(6):2101-8.

31. Thangarathinam N, Jayshree N, Vijayam, Ramanathan L. Effect of polyherbal formulation on ethylene glycol induced urolithiasis. Int. J. Pharm. Pharm. Sci. 2013;5:994-7.

32. Panigrahi PN, Dey S, Sahoo M, Dan A. Antiurolithiatic and antioxidant efficacy of Musa paradisiaca pseudostem on ethylene glycol induced nephrolithiasis in rat. IJP. 2017;49(1):77-80.

33. Borlagdan M, Aurigue FB, Van Altena IA, Ragasa CY. Triterpenes from Hoya paziae Kloppenb. Pharmacognosy Journal. 2016;8(5):487-9.

34. Gul AK, Nusrat S, Innayat UR, Murad AK, Kamal UA, Viqar UH. Naturally occurring flavonoids. Jour. Chem.Soc.Pak. 2001;23:50-60.

\section{PICTORIAL ABSTRACT}

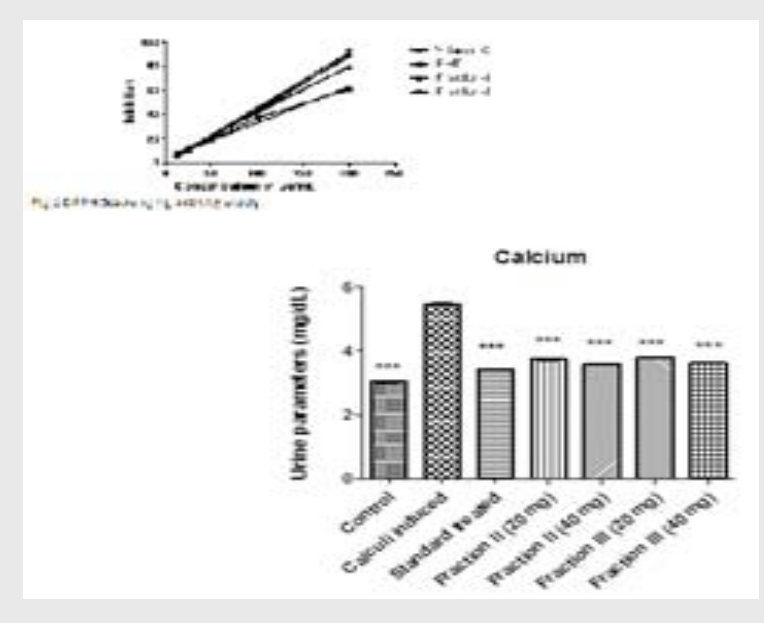

- The presen SdUMaMARdcused on bioactivity guided fractionation and carrying out its antioxidant and antiurolithiatic efficacy study. As the fractions have shown the presence of phytochemicals in the preliminary phytochemical investigations reported earlier, it was necessary to identify them in a more scientific manner by subjecting them to LCMS study. The LCMS spectra of both the fractions have shown the presence of different polyphenolic compounds around their molecular ion (based on molecular weight) as given in Table 3 . This confirmed the presence of flavonoids, glycosides, saponins etc. The important phytochemicals which may be responsible for the antioxidant and antiurolithiatic activity may be Betulin, Quercetin, ursolic acid etc which needs to be confirmed by conducting a separate study for the isolated compounds. Later, these two fractions (AEF II and AEF III) have been screened for antioxidant and antiurolithiatic potencies. These fractions have shown significant activities. This study highlights the significance of formulating specific fractions rather than the whole extracts to avoid unnecessary exposure to all the phytochemicals in the extract. 

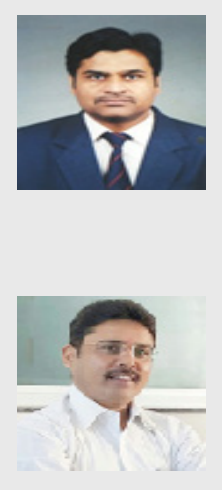

Dr.Sunil Satyappa Jalalpure: Presently serving as Professor Department of Pharmacognosy, College of Pharmacy, Belagavi and Deputy Director, Dr. Prabhakar Kore Basic Science Research Center, KAHER, Belagavi, Karnataka. He has over 23 years of teaching experience and his areas of research interests include isolation/ characterization of active principles from medicinal plants and their pharmacological screening for various biological activities and training the research students in Pharmacognosy, Phytochemistry and Biotechnological aspects with modern tools and techniques. He has published 66 Research Papers and 69 Poster presented in national and international workshops and conferences. Authored 02 nos. of books. He has delivered more than 40 invited talks on various platforms. Forty six (46) postgraduates have been successfully guided for the completion of their M.Pharm dissertation and presently guiding nine (09) Ph. D students for their thesis. Five (6) candidates successfully completed Ph.D.

Dr. Sunil Jalalpure received Best Young Scientist award for the year 2011-12 from KLE University, Belagavi and National Level Young Pharmacy Teacher Award for the year 2012 at the 17th (APTI) Association of Pharmaceutical Teachers of India Annual Convention hosted by Manipal University, Manipal, Udupi, Karnataka, on $12^{\text {th }}$ October 2012 and Best Teacher Award - 2011 from KLE University on Teacher's Day. He also received travel grant from AICTE under Young Scientist Category to present research paper in World Congress on Medicinal \& Aromatic Plants at Cape Town, South Africa. He has received financial support from various funding agencies like UGC, AICTE, DST, DBT and ICMR for research projects and for organising conferences/workshops. He is member of several pharmacy professional societies and has chaired several scientific sessions at national and international conferences. He has worked as organising secretary for several national and international conventions. He has been invited to visit Australia, Thailand, Malaysia and South Africa to attend and present research papers at conferences. Recently awarded by STAR award and received APTI Pharmacy Teacher award -2017 instituted by Bharati Vidyapeeth CoP, Pune (above 40 yers of age).

Cite this article: Dinnimath BM, Jalalpure SS. Antioxidant and Antiurolithiatic Efficacy of Aerva lanata (L) Fractions by in vitro and in vivo Screening Techniques. Indian J of Pharmaceutical Education and Research. 2018;52(3):42636. 